\title{
Osteoporosis: a Common Health Problem in Senior Adult Population of Arar City, Saudi Arabia
}

\author{
Abdalla Mohamed Bakr Ali ${ }^{1}$, Amal Mahmoud R. Abdullah ${ }^{2}$, Mohammed Faleh M Alanazi ${ }^{3}$, Deema \\ Faleh M Alanazi ${ }^{3}$, Reema Faleh M Alanazi ${ }^{3}$, Ahmed Mahmoud R Abdullah ${ }^{3}$, Abdullah Mohammed M \\ Alsayed $^{2}$, Rema Jamal Alotaibi ${ }^{2}$, Mays Nawaf F. Alharbi ${ }^{2}$, Luluah Maan R Abdullah ${ }^{3}$, Ghaida Abdullah \\ Rasheed Alshamlani ${ }^{3}$ \\ ${ }^{1}$ Faculty of Medicine, Sohag University, Egypt, ${ }^{2}$ Faculty of Medicine, Arabian Gulf University, Bahrain, ${ }^{3}$ Faculty of \\ Medicine, Northern Border University, KSA \\ apdo3332008@gmail.com
}

\begin{abstract}
Background: Osteoporosis is characterized by compromised bone strength predisposing to an increased risk of fracture, which has significant effects on human health, quality of life. Objective: To determine the prevalence and determinant factors of osteoporosis among elderly in Arar, KSA. Methods: The present cross sectional community based study was conducted in Arar city, the capital of Northern Borders Governorate on 229 adult people aged 60 years and more. Data were collected through personal interviews with the sampled population and filling the questionnaire which guided us to the data of socio-demographic status, smoking, chronic diseases, already previously diagnosed osteoporosis, after ensuring the diagnosis by reviewing the accompanied health reports and/or prescriptions and asking the accompanied caregivers about the case. Results: The mean age of the participants $( \pm$ SD) was $70.5( \pm 9.4)$ years. Males were $48 \%$ and females were $52 \%$. The overall prevalence rate of osteoporosis found in this study was $24.5 \%$. There was significant relationship between osteoporosis and sex, presence of thyroid disease $(\mathrm{P}<0.05)$. While there was an insignificant relationship between osteoporosis and age group, BMI group, presence of diabetes mellitus and presence of hypertension $(\mathrm{P}>0.05)$. Conclusion: In conclusion, osteoporosis is a common health problem (24.5\%) in the elderly population in Arar city, KSA. Conclusion: Osteoporosis is significantly higher in elderly females. Health education and preventive programs are highly recommended to protect and treat that vulnerable group.
\end{abstract}

Keywords: Osteoporosis; Elderly; Saudi Arabia

\section{INTRODUCTION}

Osteoporosis is a progressive systemic noncommunicable skeletal disorder that is associated with significant mortality, morbidity and costs of management. It is characterized by decreased bone mass due to an imbalance between bone formation and resorption and increased risk of fracture. The World Health Organization referred to osteoporosis as "an epidemic of the $21^{\text {st }}$ century ${ }^{[1]}$." Osteoporosis has a diagnostic criterion based on the measurement of bone mineral density (BMD) ${ }^{[2]}$, as it is the only test that can diagnose osteoporosis before a bone fracture occurs. Since the BMD distribution in young healthy individuals is normal and the bone loss occurs along with aging, the prevalence of osteoporosis increases with age. Trends on the prevalence of osteoporosis are published throughout time and are increasing as more focus and attention are paid towards such common diseases.

Since the world healthcare systems are aiming to increase the life expectancy of individuals, an increase in osteoporotic patients is expected. A study carried out in Sweden showing the prevalence of osteoporosis in men and women aged 50-84 using the WHO criterion to be $6.3 \%$, and $21.2 \%$ of population, respectively ${ }^{[3]}$. Also, according to the $\mathrm{WHO}, 55 \%$ of the population in the USA aged over 50 years suffer from osteoporosis ${ }^{[4]}$. Among women in Saudi Arabia, the incidence of post-menopausal osteoporosis (PMO) is higher in comparison with women in Western countries ${ }^{[5-7]}$. Among men, however, a study found that $24.3 \%$ of Al-Khobar (city in Saudi Arabia) subjects attending outpatient clinics at King Fahd Hospital University, aged 50-76 years were osteoporotic, based on hip scans, and $37.4 \%$, based on scans on the lumbar spine ${ }^{[8]}$.

Early diagnosis and management of osteoporosis can prevent its complications, mainly, osteoporosis-related fractures (ORF), and decrease morbidity and mortality rates in those senile patients.

The aim of this prospective study was to assess the prevalence and determinant factors of osteoporosis in the senior adult population of Arar city, Saudi Arabia, based on the physicians' diagnoses and using a pre-designed questionnaire.

\section{STUDY OBJECTIVE}

The aim of this study was to determine the prevalence and determinant factors of osteoporosis among elderly in Arar, KSA. 


\section{PARTICIPANTS AND METHODS}

The present cross sectional community based study was conducted in Arar city, the capital of Northern Borders Governorate on 229 adult people aged 60 years and more. The sample size was calculated using the sample size equation: $\mathrm{n}=\mathrm{z}^{2} \mathrm{p}(1-\mathrm{p}) / \mathrm{e}^{2}$, considering target population more than 1000, and study power 95\%. Systematic random sampling technique was followed. After identifying the first house randomly in the selected area, every 9th house was visited to include all the adult subjects residing in those selected houses till the required sample was covered.

\section{Data collection:}

Data were collected through personal interviews with the sampled population and filling the questionnaire which guided us to the data of socio-demographic characteristics such as age, sex, educational status and marital status. It also included smoking status and certain chronic diseases that may be prevalent among adults suggested to affect osteoporosis such as obesity, hypertension, diabetes milletus and hyperlipidemia. The questionnaire included also questions regarding the already previously diagnosed osteoporosis and its determinants, after ensuring the diagnosis by reviewing the accompanied health records and prescriptions and asking the accompanied caregivers about the case.

\section{Ethical considerations}

Data collector gave a brief introduction to the participants by explaining the aims and benefits of the study. Informed written consent was obtained from all participants. Anonymity and confidentiality of data were maintained throughout the study. There was no conflict of interest.

\section{Statistical analysis}

We utilized the statistical package for social sciences, version 16 (SPSS Inc., Chicago, Illinois, USA) to analyze the study data. The results were displayed as counts and percentages. The $\mathrm{X} 2$ test was used as a test of significance, and differences were considered significant at $P$ value less than 0.05 .

\section{RESULTS}

Table (1) illustrates the sociodemographic characteristics and BMI status of the studied elderly population. The mean age $( \pm$ SD) was 70.5 $( \pm 9.4)$ years. Males were $48 \%$ and females were $52 \%$. Married participants were the majority $(60.3 \%)$ while $34.5 \%$ were widowed. Illiteracy constituted $45 \%$, primary school literates were $19.7 \%$.As regards working, $64.6 \%$ were not working and $19.7 \%$ were retired, while only $15.7 \%$ were shepherds.

Table (2) demonstrates the prevalence of osteoporosis and other related chronic diseases among the studied population. Hypertension was found in $43.7 \%$, ischemic heart diseases in $17.9 \%$, hypothyroidism in $12.2 \%$, diabetes $62.9 \%$, diabetic nephropathy in $4.8 \%$ and renal insufficiency in $6.1 \%$. As regards the BMI, about half (43.7\%) were obese, $27.9 \%$ overweight and only $24.9 \%$ had normal weight.

Figure (1) shows the percentage distribution of osteoporosis among the elderly population. The overall prevalence rate of osteoporosis found in this study was $24.5 \%$.

Table 3 displays the relationship between Osteoporosis and age group, sex, DM, BMI group, Thyroid disease and Hypertension in the studied elderly population. It is clear from the table that there was significant relationship between osteoporosis and sex, presence of thyroid disease $(\mathrm{P}<0.05)$. While there was an insignificant relationship between osteoporosis and age group, BMI group BMI group presence of diabetes mellitus and presence of hypertension $(\mathrm{P}>0.05)$.

Table (1): Socio-demographic characteristics and smoking among the studied elderly, Arar, 2017 (N=229).

\begin{tabular}{|l|c|c|}
\hline \multicolumn{1}{|c|}{ Variables } & Frequency (No.) & Percent (\%) \\
\hline Age group & 142 & 62.0 \\
\hline $60-$ & 64 & 27.9 \\
\hline $70-$ & 23 & 10.0 \\
\hline $80+$ & \multicolumn{2}{|c|}{$70.5 \pm 9.4$} \\
\hline Mean age \pm SD) & \multicolumn{2}{|c|}{} \\
\hline Sex & 119 & 52.0 \\
\hline Female & 110 & 48.0 \\
\hline Male & \multicolumn{1}{|c|}{} \\
\hline Education & 103 & 45.0 \\
\hline Illiterate & 45 & 19.7 \\
\hline Primary & 22 & 9.6 \\
\hline Secondary & 41 & 17.9 \\
\hline University or more & 18 & 7.9 \\
\hline Preparatory & & 15.7 \\
\hline Working status & 36 & 64.6 \\
\hline Shepherd & 148 & 19.7 \\
\hline No work & 45 & 34.5 \\
\hline Retired & & 2.6 \\
\hline Marital status & 79 & 60.3 \\
\hline Widow & 6 & 2.6 \\
\hline Single & 138 & \\
\hline Married & 6 & \\
\hline Divorced & & \\
\hline & & \\
\hline
\end{tabular}


Table (2): Prevalence of osteoporosis and other related chronic diseases among the studied elderly population, Arar, 2017 ( $\mathrm{N}=229)$

\begin{tabular}{|l|c|c|}
\hline \multicolumn{1}{|c|}{ Osteoporosis } & No. & $\%$ \\
\hline Yes & 56 & 24.5 \\
\hline No & 173 & 75.5 \\
\hline Cardiovascular diseases & & \\
\hline Hypertension & 100 & 43.7 \\
\hline Ischemic heart diseases & 41 & 17.9 \\
\hline Thyroid diseases & & \\
\hline Hyperthyroidism & 12 & 5.2 \\
\hline Hypothyroidism & 28 & 12.2 \\
\hline Diabetes & & \\
\hline Yes & 144 & 62.9 \\
\hline No & 44 & 19.2 \\
\hline Renal problems & & \\
\hline Diabetic nephropathy & 11 & 4.8 \\
\hline Renal insufficiency & 14 & 6.1 \\
\hline Body Mass Index (kg/m2) status & & \\
\hline Underweight & 8 & 3.5 \\
\hline Normal & 57 & 24.9 \\
\hline Overweight & 158 & \\
\hline Obese & 55.9 & \\
\hline Mean BMI ( SD) & 16 & \\
\hline Smoking & & \\
\hline Non smoker & & \\
\hline Smokers & & \\
\hline Ex-Smoker & & \\
\hline & & \\
\hline
\end{tabular}

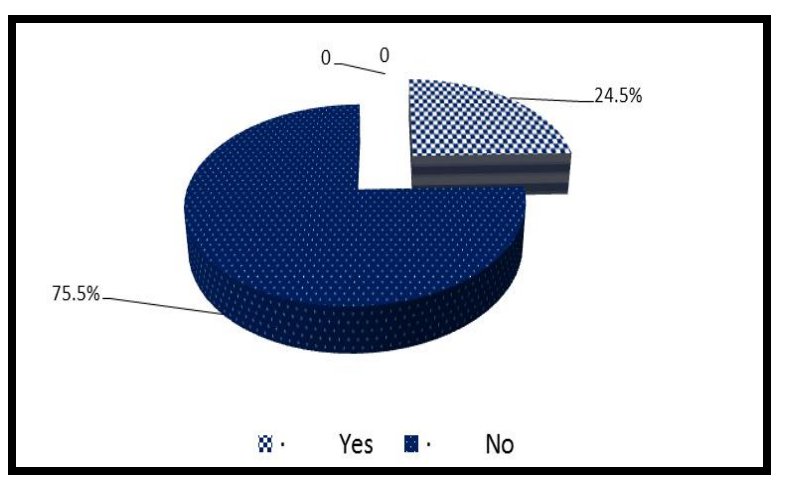

Figure (1): Prevalence of Osteoporosis among elderly population in Arar city, Northern Saudi Arabia, 2017.
Table (3): The relationship between Osteoporosis and age group, sex, DM, BMI group, Thyroid disease and Hypertension in the studied elderly population, Arar, 2017.

\begin{tabular}{|c|c|c|c|c|}
\hline \multirow[b]{2}{*}{ Variables } & \multicolumn{2}{|c|}{ Osteoporosis } & \multirow[b]{2}{*}{$\begin{array}{c}\text { Total } \\
(\mathrm{N}=229)\end{array}$} & \multirow[b]{2}{*}{$\begin{array}{c}\mathrm{P} \\
\text { value }\end{array}$} \\
\hline & $\begin{array}{c}\text { Yes } \\
(\mathrm{N}=65)\end{array}$ & $\begin{array}{c}\text { No } \\
(\mathrm{N}=173)\end{array}$ & & \\
\hline \multicolumn{5}{|l|}{ Age group } \\
\hline \multirow{2}{*}{$60-$} & 35 & 107 & 142 & \multirow{6}{*}{0.961} \\
\hline & $62.5 \%$ & $61.8 \%$ & $62.0 \%$ & \\
\hline \multirow{2}{*}{ 70- } & 15 & 49 & 64 & \\
\hline & $26.8 \%$ & $28.3 \%$ & $27.9 \%$ & \\
\hline \multirow{2}{*}{$80+$} & 6 & 17 & 23 & \\
\hline & $10.7 \%$ & $9.8 \%$ & $10.0 \%$ & \\
\hline \multicolumn{5}{|l|}{ Sex } \\
\hline \multirow{2}{*}{ Female } & 43 & 76 & 119 & \multirow{4}{*}{0.001} \\
\hline & $76.8 \%$ & $43.9 \%$ & $52.0 \%$ & \\
\hline \multirow{2}{*}{ Male } & 13 & 97 & 110 & \\
\hline & $23.2 \%$ & $56.1 \%$ & $48.0 \%$ & \\
\hline \multicolumn{5}{|l|}{ Diabetes Mellitus } \\
\hline \multirow{2}{*}{ Yes } & 37 & 107 & 144 & \multirow{2}{*}{0.848} \\
\hline & $66.1 \%$ & $61.8 \%$ & $62.9 \%$ & \\
\hline \multirow{2}{*}{ No } & 10 & 34 & 44 & \\
\hline & $17.9 \%$ & $19.7 \%$ & $19.2 \%$ & \\
\hline \multicolumn{5}{|l|}{ Thyroid disease } \\
\hline \multirow{2}{*}{ Hyperthyroidism } & 6 & 6 & 12 & \multirow{6}{*}{0.001} \\
\hline & $10.7 \%$ & $3.5 \%$ & $5.2 \%$ & \\
\hline \multirow{2}{*}{ Hypothyroidism } & 16 & 12 & 28 & \\
\hline & $28.6 \%$ & $6.9 \%$ & $12.2 \%$ & \\
\hline \multirow{2}{*}{ No thyroid disease } & 34 & 155 & 189 & \\
\hline & $60.7 \%$ & $89.6 \%$ & $82.5 \%$ & \\
\hline \multicolumn{5}{|l|}{ BMI group } \\
\hline \multirow{2}{*}{ Underweight } & 4 & 4 & 8 & \multirow{8}{*}{0.068} \\
\hline & $7.1 \%$ & $2.3 \%$ & $3.5 \%$ & \\
\hline \multirow{2}{*}{ Normal } & 11 & 46 & 57 & \\
\hline & $19.6 \%$ & $26.6 \%$ & $24.9 \%$ & \\
\hline \multirow{2}{*}{ Overweight } & 11 & 53 & 64 & \\
\hline & $19.6 \%$ & $30.6 \%$ & $27.9 \%$ & \\
\hline Ohese & 30 & 70 & 100 & \\
\hline Ubese & $53.6 \%$ & $40.5 \%$ & $43.7 \%$ & \\
\hline Hypertension & & & & \\
\hline Yes & 23 & 77 & 100 & \\
\hline Yes & $41.1 \%$ & $44.5 \%$ & $43.7 \%$ & \\
\hline $\mathrm{No}$ & 33 & 96 & 129 & 0398 \\
\hline & $58.9 \%$ & $55.5 \%$ & $56.3 \%$ & \\
\hline
\end{tabular}

\section{DISCUSSION}

Osteoporosis is characterized by compromised bone strength predisposing to an increased risk of fracture, which has significant effects on human health, quality of life (QoL) ${ }^{[9,10]}$.It was estimated in the year 2000 that there were about 9 million osteoporotic fractures, most of which were occurring in Europe ${ }^{[9]}$. Billions of dollars are spent by the Western nations on the complications of osteoporosis. It is necessary to run more studies concerning osteoporosis. In this study we found that $24.5 \%$ of the study population were suffering from osteoporosis. 
The population of our study aged $>50$ years with a mean age $( \pm$ SD) of $70( \pm 9.4)$. Slightly more females contributed to the study as the male to female ratio was 12:13. Most of the participants do not work $(64.6 \%)$, and are married (60.3\%). More females (55.9\%) than males were also found in Al-Modeer $\boldsymbol{e t}$ $\boldsymbol{a l}^{[11]}$ study in Southern Saudi Arabia, where the mean age $( \pm \mathrm{SD})$ was $77.2( \pm 8.9)$

Among our study population, $45 \%$ were illiterates. This was higher than the finding of Khadervalli et $\boldsymbol{a l}{ }^{[12]}$ who reported only $27 \%$ illiteracy in Kadappa region of South India.

A significant association between sex and Osteoporosis was markedly revealed in this study. Osteoporosis was more common in females than males (76.8\% and 23.2\%) respectively $(\mathrm{P}<0.05)$. The study of AlModeer et al. which was conducted in the south Saudi Arabia, has shown that osteoporosis was found in $17.4 \%$ and it was more prevalent among elderly females (29.5\%) compared to males $(14.5 \%)^{[11]}$. These findings also agree with those of Hassan ${ }^{(13)}$, in which $2.2 \%$ of females and $0.8 \%$ of males had the disease, although the figures were far less than our figures ${ }^{[13]}$. The sharp decrease in Estrogen hormone levels at the age of menopause, along with the physiology of female bones which makes them normally slightly thinner than males are main contributors to these findings observed in elderly females diseased with osteoporosis.

\section{CONCLUSION \& RECOMMENDATIONS}

In conclusion, osteoporosis is a relatively common disorder in the elderly population in Arar city, KSA. It is significantly higher in elderly females. We highly recommend preventive programs and health awareness campaigns to protect and treat those vulnerable groups.

\section{REFERENCES}

1. World Health Organization (1994): Assessment of fracture risk and its application to screening for postmenopausal osteoporosis. http:// www. who. int/ iris/handle/10665/39142

2. Kanis JA, Melton LJ, III, Christiansen C, Johnston CC, Khaltaev N (1994): The diagnosis of osteoporosis. J Bone Miner Res., 9:1137-1141.

3. Kanis JA, Johnell O, Oden A, Jonsson B, De Laet C, Dawson A (2000): Risk of hip fracture according to the World Health Organization criteria for osteopenia and osteoporosis. Bone, 27:585-590.
4. National Osteoporosis Foundation. (2002): America's Bone Health: The State of Osteoporosis and Low Bone Mass in Our Nation. Washingron DC: National Osteoporosis Foundation. https:// www. nof.org/

5. Sadat-Ali M, Al-Habdan I, Al-Mulhim FA, ElHassan AY (2005): Effect of parity on bone mineral density among postmenopausal Saudi Arabian women. Saudi Med J., 26: 1588-90.

6. El-Desouki M (2003): Osteoporosis in postmenopausal Saudi women using dual x-ray bone densitometry. Saudi Med J., 24(9): 953-56.

7. Sadat-Ali-M, Al-Habdan I, Marwah S (1996): Bone mineral density measurement of distal radius in Saudi Arabian females. Ann Saudi Med., 16:414-16.

8. Sadat-Ali M, AlElq A (2006): Osteoporosis among Male Saudi Arabs: A Pilot Study. Ann Saudi Med., 26(6): 450-454.

9. Johnell O, Kanis J (2006): An estimate of the worldwide prevalence and disability associated with osteoporotic fractures. Osteoporos Int., 17:1726-1733.

10. Hernlund $\mathrm{E}$, Svedbom A, Ivergård $\mathrm{M}$ et al. (2013): Osteoporosis in the European Union: medical management, epidemiology and economic burden. A report prepared in collaboration with the International Osteoporosis Foundation (IOF) and the European Federation of Pharmaceutical Industry Associations (EFPIA) Arch Osteoporos., 8:136.

11. Al-Modeer A, Noha S, Chauky M(2013): Profile of morbidity among elderly at home health care service in Southern Saudi Arabia. J Family Community Med., 20(1): 53-57.

12. Khadervali N, Bhagavathula AS, Raziya D, Ramsagarreddy, Kuldeep S. (2014): Comparative study of health status among slum and non-slum elderly population in Kadappa region. South India Journal of Evolution of Medical and Dental Sciences, 3(5):1298-1307.

13. Hassan $S$ (2015): A study of morbidity pattern among geriatric population in Fayoum Governorate, Egypt. Journal of American Science, 11:90-95. 